\title{
Safe Sojourns to High Altitudes: The Risks of Annual Religious Pilgrimages in Jammu and Kashmir, India- Clinical Diagnostics and Treatment
}

\author{
SM Kadri ${ }^{1 *}$, Saleem-ur-Rehman ${ }^{2}$, Michael W Popejoy ${ }^{3}$ and Christoph S Eberle ${ }^{4}$ \\ ${ }^{1}$ Division of Epidemiology and Public Health, Integrated Disease Surveillance Programme, India \\ ${ }^{2}$ Department of Health Services, Fellow WHO Director, India \\ ${ }^{3}$ Department of Health Promotion and Disease Prevention, Florida International University, USA \\ ${ }^{4}$ National Academy of Clinical Biochemistry, Associate Fellow, USA
}

Submission: May 04, 2017; Published: May 26, 2017

*Corresponding author: SM Kadri, Division of Epidemiology and Public Health, RFPTC Building, Barzulla, Srinagar 190005, Kashmir, India, Email: Kadrism@gmail.com

\begin{abstract}
This article addresses the clinical diagnosis and clinical treatment plan for several diseases that afflict high altitude climbers and the increasing prevalence for this type of illness. In The behavioral characteristics of high altitude climbers and the precautions necessary to prevent death from the high altitude sport activities are introduced; first; then. The clinical manifestations of different disease complexes are described; then, the common treatment regimens for climbermal adaptation for high altitude sickness are covered. The conclusion explored in the discussion is that no one need die from high altitude sickness if proper planning and good judgment are applied to climbing protocols; and, that these rules are strictly adhered to. The ends state for a reasonably guaranteed good outcome. Survival is simply to immediately descend to a lower altitude unless bad weather or climber injuries prevent immediate descent.
\end{abstract}

Keywords: AMS; HAPE; HACE; Hemoglobin; Oxygenation; Pulmonary and Cerebral Diseases

\section{Introduction}

The increased prevalence of high altitude sickness such as Acute Mountain Sickness (AMS), High Altitude Cerebral Edema (HACE), and High Altitude Pulmonary Edema (HAPE) are related to the increasing popularity of mountain climbing as an adventure sport; and the increasing ease, and decreasing cost of travel to popular climbing tourist destinations. This precludes the usual preparations and adaptations of experienced climbers embarking on extreme ascents. Today, with the exception of these extreme climbing projects, climbers can climb mountains as a weekend activity. However, even moderate ascents can lead to the illness syndromes that are discussed here. Thus, there is an expected increase in high altitude sicknesses presented to mountain guides, first responders, and emergency department physicians located in mountainous areas.

The experienced climbers anticipating a long ascent plans the climb, gets into shape, and climbs on an acclimatization schedule lasting weeks to months. These are not weekend climbers who anticipate climbing to extreme altitudes. The experienced adventurers rarely suffer high altitude sickness; and, always at the extremes of the planned; but, even weekend climbers can climb to altitudes sufficient to cause illness when unprepared. So, those afflicted with high altitude sickness are much more likely to be inexperienced recreational climbers who have allocated less time to acclimate to the environment such as the dramatic change in altitude (Figure 1).

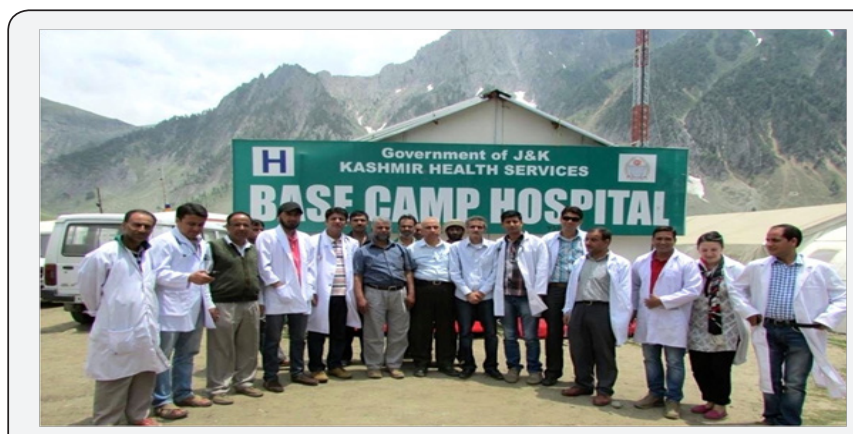

Figure 1: Team of doctors posted at base camp hospital, where the procedure was performed along with team of doctors, who were visited from Directorate of Health Services, Kashmir to appreciate the team. 
From a public health standpoint, prevention is an essential activity through an aggressive public information program including pre-climb briefings, and almost certainly inexperienced climbers should be required to climb with an experienced guide who knows how to identify the signs of sickness, knowledge of treatment, equipped to treat the illness; and, the authority to order an immediate descent of the climbing group. Like many environmental conditions; prevention, treatment, and survival depend largely on intelligent decisions by people affected both individually and as a group. Preparation planning is critical as is planning an exit strategy from the hazardous environment. In some extremes of altitude and terrain, available rescue is almost impossible especially at extreme high altitudes beyond the safe reach of rescue helicopters. And, the time it would take for a climbing rescue team to reach the scene could arrive too late for a successful outcome (Figure 2).

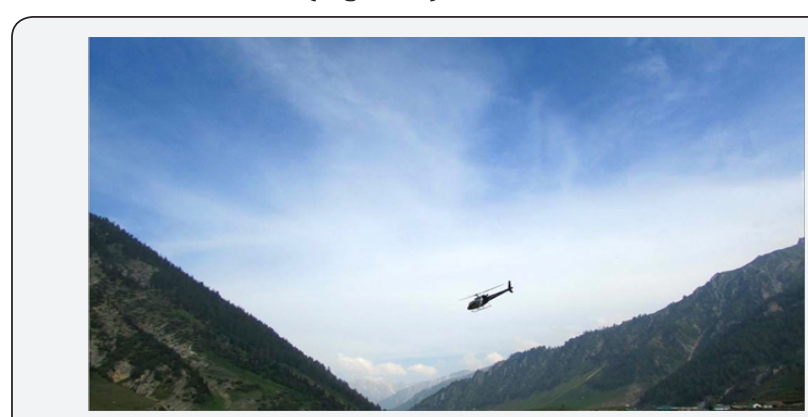

Figure 2: Panoramic view of Baltal area, here the chopper is carrying pilgrims to Panjtarni en route to holy cave of Amarnath $\mathrm{Ji}$.

As adaptation and clinical symptoms and treatment of High Altitude Diseases are discussed, it is important to note that no one need die if appropriate precautions are taken. Extreme climbers in the "Death Zone" of Mt. Everest may die because no one can help them down and their often irrational commitment to summit creates a psychological conflict between the climb or descend decisions quickly while the afflicted climber can still walk. Also at work is the neurological dysfunction that can impair judgment and decision making at a critical time. Sometimes, the choice is to force the climber down or write them off as on their own; and, likely a lost soul on the mountain. There are dozens of frozen bodies on Mt. Everest and other extreme mountains as evidence to this effect.

\section{The Pathophysiology of High Altitude Sickness}

According to the barometric formula, air pressure exponentially decreases at increasing altitudes; a phenomenon, which causes high altitude sickness [1]. It occurs as an acute or chronic condition depending on the time and speed of exposure to high altitude. If an acute condition prevails, symptoms can worsen to both a high altitude pulmonary edema (HAPE) [2] and a high altitude cerebral edema (HACE) [3]. Both complications are rare; but, life-threatening. Though these disease conditions are well described, clinically, their partially overlapping pathomechanisms need to be differentiated [4] (Figure 3).

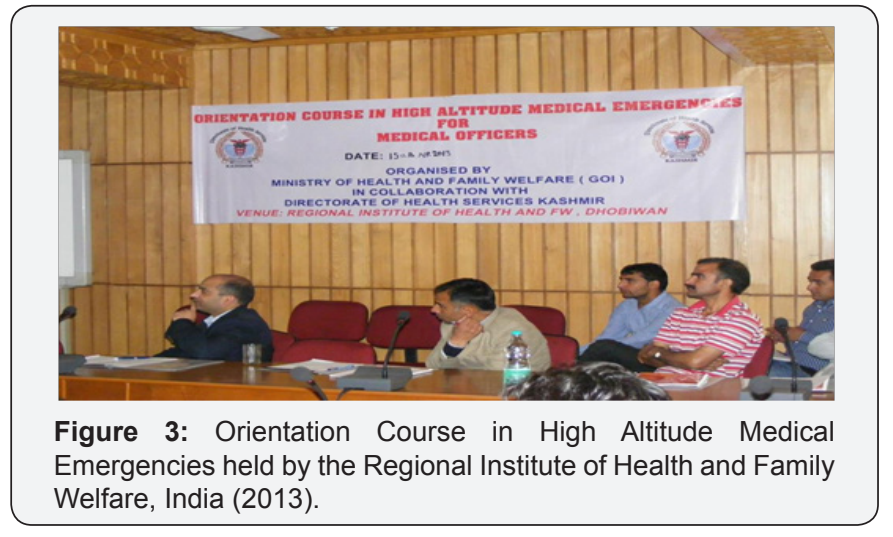

When ascending to high altitudes, the oxygen partial pressure in the lungs is reduced, whereas the carbon dioxide partial pressure remains constant. Therefore, hemoglobin is less saturated with oxygen, thus leading to generalized hypoxia. In this situation, pulmonary arteries constrict resulting in hypertension and fluid imbalances. These effects on hemodynamic caused by a hypoxic environment turn out to be pathognomonic in susceptive individuals. Consequently, all compensatory measures of metabolism aim at increasing the oxygen concentration in the blood. On the one hand, the endocrine system triggers erythropoietin (EPO) excretion from the kidney as response to lower oxygenation. EPO stimulates the production of erythrocytes in the bone marrow. This hormone signal seems to be potentiated by hypoxia-inducible factor 1 (HIF-1), which takes part in intrinsic formation of nitric oxide, a second messenger that promotes vasodilation [5].

As hemoglobin biosynthesis is also accelerated, more potential oxygen binding sites are made available, as indicated by elevated hematocrite levels and other standard red blood cell count (RBC) parameters. However, this compensatory erythrocytosis is known to be reversible. It corresponds with higher intestinal iron absorption and reticulocytosis [6] but; the expansion of red blood cell volume requires the heart to pump at higher rates and making potentially dangerous clot formation more likely. Besides increasing the binding capacity, hyperventilation occurs to increase oxygen absorption in the lungs. However; by this reflex, only carbon dioxide is breathed out more rapidly progressing to respiratory alkalosis [7]. Since as a result less carbon dioxide can be converted into carbonic acid, the volatile bicarbonate buffering system in the blood is out of its equilibrium. Due to a reduced concentration of bicarbonate and hydrogen ions buffering capacity is lost, and the arterial blood $\mathrm{pH}$ turns alkaline $(>7 \cdot 38)$.

Temporarily, this $\mathrm{pH}$ shift can be metabolically counterbalanced to retain bicarbonates both by renal excretion and decelerating the urea cycle in the liver. Usually, acidbase imbalances compensated by the kidneys take effect later than hepatic mechanisms. The alkaline blood $\mathrm{pH}$ lowers the hemoglobin affinity to oxygen, as indicated by a right shift of the equilibrium curve with an increased P50. Simultaneously, 
glycolysis in red blood cells is activated producing more of the intermediate 2, 3-disphosphoglycerate (2, 3-DPG), an allosteric regulator of hemoglobin [8]. 2, 3-DPG binds to its partially deoxygenated state (T conformation), which facilitates the release of already bound oxygen molecules. By keeping hemoglobin in a conformation, which is more likely to unload oxygen, 2, 3-DPG mediates sufficient supply of hypoxic tissues as long as this is required. Therefore, this allosteric mechanism contributes to the gradual acclimatization to high altitudes, which proves to be an evolutionary benefit in animals adapted to such an extreme habitat [9].

It is critical that emergency medical workers located in the shadows of high ascent areas of the world be constantly trained in the recognition and response to high altitude sickness. An intensive Orientation Course in High Altitude Medical Emergencies was started for Medical Officers at RIHFW (Figure 1). Active Amarnath Ji Yatra Management by Directorate of Health Services Kashmir, India led to drastic reductions in pilgrim deaths this year (Figure 4).

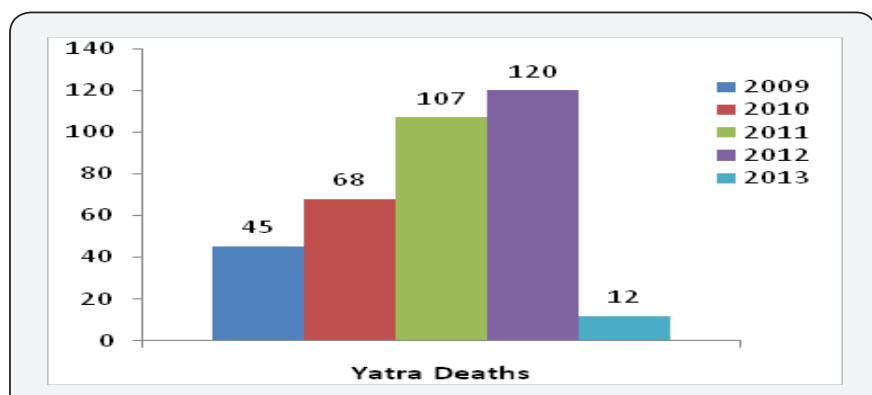

Figure 4: Total numbers of reported yatra deaths due to high altitude sickness (2009 - 2013).

In year 2014 Total piligrims visited the holy shrine are: 4,53,000 Number of deaths: 48

In year 2015 Total piligrims visited the holy shrine are: $3,67,000$ Number of deaths : 43

In year 2016 Total piligrims visited the holy shrine are: $2,16,000$ Number of deaths : 16

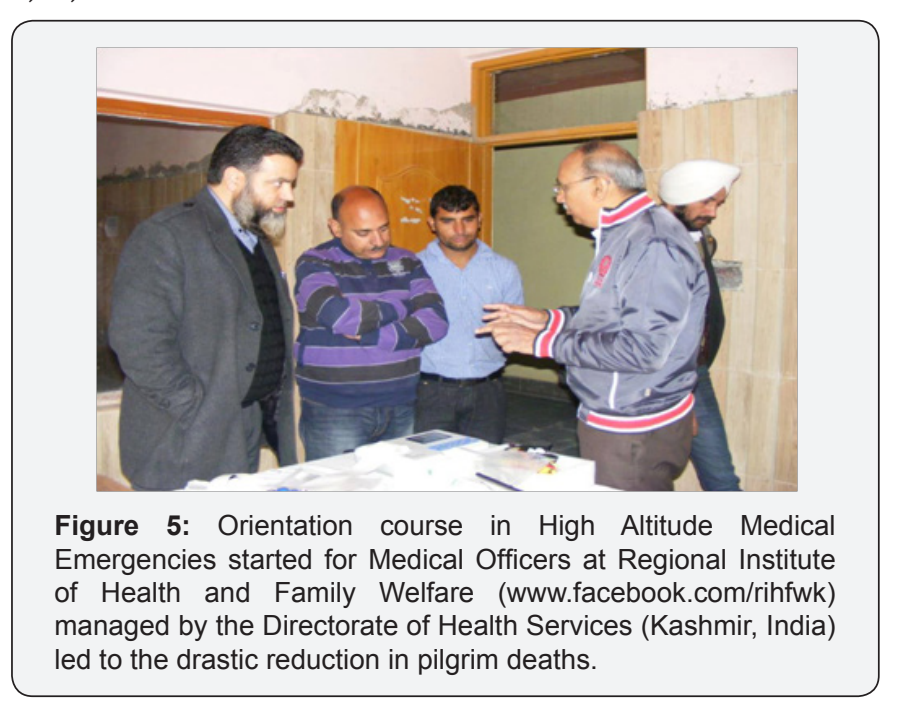

Programs of this kind can continue to reduce deaths among inexperienced tourists and pilgrims seeking a high altitude ascent regardless of purpose [10]. Of course, it is also critical that climber's guides and climbing club managers also exercise authority over those who insist on climbing often without adequate preparation, skills, or supervision. Of course, this authority may be codified and enforced by local government regulation and licensing of guides and formal legal approval of all climbing group expeditions ensuring that all standards and safeguards have been met (Figure 5).

\section{Travel Safe to High Altitudes}

\section{Introduction to Safe Travel}

Every year millions of people travel to high altitude for recreation, religious purposes and for work. Those travelling to altitudes $5500 \mathrm{~m} / 18,000$ feet, twenty percent of them suffer from acute mountain sickness (AMS). This number goes to fifty percent above 18,000 ft. Most cases of AMS are mild and selflimiting but some cases become life threatening. Once travelling or planning to travel to high altitude (above $5500 \mathrm{M} / 18,000$ feet) knowledge plays an important role in the prevention of AMS. High altitude area (HAA) is divided into High altitude, Intermediate altitude, very high altitude and extreme high altitude depending on height as explained below (Table 1).

Table 1: High altitude area (HAA) is divided into High altitude, Intermediate altitude, very high altitude and extreme high altitude depending on heights.

\begin{tabular}{|c|c|c|}
\hline Altitude & Height & Illness \\
\hline $\begin{array}{c}\text { Intermediate } \\
\text { altitude }\end{array}$ & $1500-2500 \mathrm{~m}$ & $\begin{array}{c}\text { Arterial oxygen saturation } \\
>90 \text { percent, acute illness } \\
\text { possible but rare }\end{array}$ \\
\hline High altitude & $2500-3500 \mathrm{~m}$ & $\begin{array}{c}\text { Altitude illness common } \\
\text { with rapid ascent }\end{array}$ \\
\hline Very high altitude & $3500-5800 \mathrm{~m}$ & $\begin{array}{c}\text { Altitude illness common, } \\
\text { Arterial oxygen saturation } \\
<90 \text { percent, marked } \\
\text { hypoxemia during exercise }\end{array}$ \\
\hline Extreme altitude & $>5800 \mathrm{~m}$ & $\begin{array}{c}\text { Marked hypoxemia } \\
\text { at rest, progressive } \\
\text { deterioration despite } \\
\text { maximal acclimatization } \\
\text { permanent survival cannot } \\
\text { be maintained }\end{array}$ \\
\hline
\end{tabular}

Many religious high altitude travels are being taken by pilgrims all over the globe and one such travel taken every year in the northern state of India is Jammu and Kashmir is Amarnath Ji Yatra where millions of people climb to the holy cave. Every year hundreds of deaths of pilgrims occur because of the lack of knowledge about the risks of travel to high altitudes. In order to reduce the mortality and morbidity new initiatives were taken by the Government of India by the Ministry of Health and Family Welfare under the guidance of the Supreme Court (Highest Court in India) framed guidelines to make the trip of pilgrims safer. A team of health professionals which included Chest Specialists, Orthopaedicians, and Public Health Experts visited the valley 
of Kashmir to train doctors who are to be on duty on the track of Amarnath Ji Yatra leading to holy cave. A total of 57 Medical Doctors in batches of three were trained at the training and research center for doctors at Regional Institute of Health and Family Welfare, Dhobiwan, District Baramulla, the Institute which is en route to the health resort of the world known as Gulmarg. The main objective of the training was management of high altitude illnesses which include AMS (Acute mountain sickness), HAPE (High Altitude Pulmonary Edema), and HACE (High Altitude Cerebral Edema) (Figure 6).

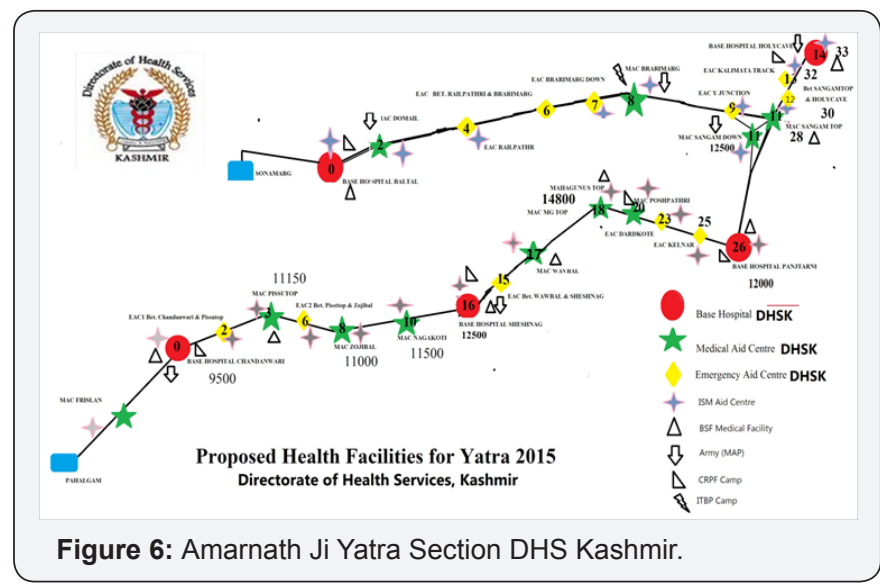

Conclusion

The world's breath taking sites exist at high altitudes and whether one plans an expedition or a religious trip, altitude illness must be a factor while planning the trip. This commentary is an introduction to recognize and respond to high altitude illness. Most of HAI (High Altitude Illness) is mild and self-limiting so be prepared for discomfort, and be prepared to recognize signs of serious illness. In the year (2012), the total number of deaths recorded were 120 related to high altitude sickness while as this year 2013, the total number of death were 12 [10], and there has been definitely the impact of good training, good infrastructure provided, and proper planning done by K- RICH (Kashmir Innovation Committee for Health Care).

\section{Recommendations}

a. Strict screening of pilgrims at the entry point; and people suffering from COAD (Chronic Obstructive Airway Diseases) should not be allowed to take the pilgrimage.

b. Strict instructions must be given to pilgrims regarding personal clothing, personal hygiene and proper hand washing

c. Essential drugs which play an important role in reducing the mortality at high altitude namely Acetazolamide, Dexamethasone and Nifedipine to be provided in ample quantity

d. Vaccination especially for Influenza and meningococcal meningitis should to be given to the pilgrims.

\section{Preventing Mountain Sickness}

i. Acute mountain sickness (AMS) depends on elevation, rate of ascent and individual susceptibility.

ii. Most visitors suffer from some symptoms that will generally disappear through acclimatization in several hours to several days.

iii. Symptoms are worse at night and include headache, dizziness, lethargy, loss of appetite, nausea, breathlessness and irritability. Difficulty sleeping is another common symptom, and many travelers have trouble sleeping for the first few days.

iv. AMS can be very serious, with the most serious symptoms being High Altitude Pulmonary Edema (HAPE) and High Altitude Cerebral Edema (HACE), which can be fatal. Symptoms of HAPE include weakness, shortness of breath, even at rest, impending suffocation at night, and a persistent productive cough with white, watery, or frothy fluid. Symptoms of HACE may include headache, ataxia, weakness, hallucinations, psychotic behavior, coma and loss of memory. Both often approach and strike at night and can be fatal! Immediate descent is the surest treatment.

v. A gradual ascent allows the body to acclimatize to higher altitudes and the decreased oxygen supply.

vi. The formula is to give a night halt between 7000 to 10,000 feet; night halt for every 1500 feet climb and full day halt for every 3000 feet climb thereafter.

vii. Medication also helps to prevent AMS.

viii. One should avoid exercise in the first few days. Attempt to do only half of the physical activities on the first day while the body is working to acclimatize to higher altitude oxygen conditions.

ix. No alcohol in the first few days.

X. No smoking.

xi. Drink enough water each day so that urine runs clear.

xii. Make sure to get enough calories. Low calorie diets at high altitudes can sabotage health. A well-nourished body can adjust to changes better than an undernourished one. One should take high carb diet.

xiii. One should avoid taking tranquilizers and sleeping pills. These will depress the respiratory drive and limit oxygen intake.

xiv. Prophylactic drugs are Acetazolamide, Nifedipine etc.

\section{References}

1. Netzer N, Strohl K, Faulhaber M, Gatterer H, Burtscher M (2013) Hypoxia-related altitude sickness. J Travel Med 20(4): 247-255. 
2. Maggiorini M (2006) High altitude-induced pulmonary oedema. Cardiovascular Res 72(1): 41-50.

3. Schommer K, Kallenberg K, Lutz K, Bartsch P, Knauth M (2013) Hemosiderin deposition in the brain as footprint of high-altitude cerebral edema. Neurology 81(20): 1776-1779.

4. Smedley T, Grocott MPW (2013) Acute high-altitude illness: a clinically orientated review. British Journal of Pain 7(2): 85-94.

5. Wilson MH, Newman S, Imray CH (2009) The cerebral effects of ascent to high altitudes. Lancet Neurol 8(2): 175-191.

6. Reynafarje C, Rodolfo L, Valdivieso J (1959) The polycythemia of high altitudes: iron metabolism and related aspects. Blood 14(4): 433-455.
7. Paulev PE, Zubieta Calleja GR (2005) Essentials in the diagnosis of acidbase disorders and their high altitude application. J Physiol Pharmacol 56(4): 155-170.

8. Samaja M, Crespi T, Guazzi M, Vandegriff KD (2003) Oxygen transport in blood at high altitude: role of the hemoglobin-oxygen affinity and impact of the phenomena related to hemoglobin allosterism and red cell function. Eur J Appl Physiol 90(3-4): 351-359.

9. West JB (2006) Human responses to extreme altitudes. Intgr Comp Biol 46(1): 25-34.

10. Achievements of Directorate of Health Services (2013) Kashmir, India.

\section{Your next submission with Juniper Publishers will reach you the below assets}

- Quality Editorial service

- Swift Peer Review

- Reprints availability

- E-prints Service

- Manuscript Podcast for convenient understanding

- Global attainment for your research

- Manuscript accessibility in different formats

( Pdf, E-pub, Full Text, Audio)

- Unceasing customer service

Track the below URL for one-step submission https://juniperpublishers.com/online-submission.php 